\title{
Interpretive Openness and Climate Action in an Age of Market Environmentalism
}

\author{
Larry Lohmann \\ [a chapter for Chris Methmann, Delf Rothe, Benjamin Stephan (eds.), (De)Constructing the Greenhouse: \\ Interpretive Approaches to Global Climate Governance (forthcoming from Routledge)]
}

Action on climate change, like any other kind of politics, consists largely of a process of continuous interpretation and reinterpretation. How to understand the climate crisis? How to understand the market environmentalist policies that have become the dominant official response to it? How to understand groups and networks with which one wants to build alliances? Such questions demand openness to whatever languages, cultures, disciplines and tools can help make sense of the current impasse and open up ways out of it. This chapter draws on three interpretive approaches from the academic world that all have contributions to make.

One resource consists of the studies critical geographers and sociologists have made of a range of contemporary ecosystem service markets and other manifestations of 'market environmentalism' that do not directly relate to climate change. Such studies offer a comparative perspective on carbon markets that helps in grasping their evolution, nature and limitations. A second resource is science and technology studies and the social study of finance, particularly actor-network theory, which provide tools for understanding the ascent to prominence of such markets and for engaging with the particular forms of expert power they embody. A third resource is the body of broadly Marxist literature that tries to comprehend the conditions that make it possible for one global regime or cycle of accumulation to succeed another. This tradition of thought can help evaluate the claims of the new 'green capitalism' to be capable of overcoming - or providing a transitory 'fix' for - the trend toward catastrophic climate change.

This chapter will begin by sketching some of the immediate historical background that has contributed to the 'economisation' of the climate crisis, drawing in an abstract way on actor-network theory. It will then try to enrich this account by folding into it some comparative case-study material from the critical geography (and actor-network theory) literature. Finally, it will suggest ways in which the study of the history of accumulation regimes might help address challenges in the global warming debate. A brief conclusion will then attempt to draw the threads together.

\section{Creating Commodification-Ready Environmental Objects}

In the 1970s, global warming barely registered on the political radar. Nevertheless, the decade saw two developments that powerfully shaped subsequent official responses to the climate crisis. One was the proliferation of new environmental regulation in countries such as the US. The other was the beginnings of a growing profitability crisis that ushered in the current period of financialization and neoliberalization (Peck 2010, Mirowski and Plehwe 2010). 
These contrasting developments combined to produce a novel vector. On the one hand, it could no longer be questioned that land, water, forests and air required protection on a national, even international scale. On the other, pressures grew to roll back the 'costly' legislation of the 1970s while rolling out new regulation that could help redistribute more wealth upwards to profit-challenged private corporations (Peck and Tickell 2002). An increasingly institutionalized neoliberal consensus made it necessary to ask how much societal and environmental protection was really necessary, and for what purposes. Could protection be calibrated more precisely to business needs for the sake of greater 'balance'? Could business perhaps even produce its own conditions of production as an outright commodity, thus maximizing efficiency and launching a lucrative new economic sector into the bargain? It began to seem both necessary and possible to bring the provision of the environmental conditions for survival and production into closer alignment with what the late Giovanni Arrighi called the 'economizing logic of capitalist enterprise' (Arrighi 1994).

Institutions began to be organized in ways that devised a progressively more abstract and calculable 'environment' and integrated it with the similarly abstract, calculable 'economy' whose construction had begun in the early postcolonial era between the 1930s and the 1950s. ${ }^{1}$ Thus by 1972, the Club of Rome, alarmed by the long-term implications of resource depletion across the board, called for management of global environmental systems as a way of keeping 'the economy' going - a message that influenced the first UN conference on the environment. Environment ministries were subsequently set up in many countries and environment departments at international financial institutions. Economists and systems analysts drew diagrams with boxes or circles labelled 'the environment', often containing, contained by, situated alongside or intersecting boxes or circles representing 'the economy', while debates pitting fans of a 'steady-state economy' against advocates of 'green growth' reflected the emerging consensus that that 'environment' and 'economy' could be isolated, then commensurated with each other in a way that would allow either one to condition the other. The ecological modernization theorists of the 1980s and 1990s spoke of the simultaneous 'ecologization of economy' and 'economization of ecology' (Mol 1995): as an unprecedented number of scientists and other experts found themselves working on market quantification, an equally unprecedented number of neoclassical economists, property lawyers and enforcement agencies found themselves toiling away on environmental projects. Not only did the new environmental professionals go to work calculating the value of an abstract, external nature to production and the value of production to nature, while simultaneously expanding cost-benefit analysis in an attempt to refine earlier rough-and-ready efforts to safeguard the background conditions for societal well-being and successful business enterprise. They also joined policymakers, environmental organizations, economists, derivatives traders and green entrepreneurs in building an infrastructure to seize and trade those conditions for profit, creating new areas for economic activity in which the financial sector played a central part. Production itself was expanded to create new values, including new natures. If nature could be fully commodified and properly priced, it was argued, capitalism could be made ecologically benign. ${ }^{2}$ 
As new institutions began to produce vast numbers of hybrids or 'monsters' ${ }^{3}$ like 'statistical life', 'biodiversity credits' and 'contingent valuation', ${ }^{4}$ the English language and thinking in English themselves changed. . 'Environmental degradation' and 'environmental harm', as well as 'environmental cost' and 'environmental benefit,' started to come into widespread use about 1965, becoming rapidly more popular from about 1980. The term 'environmental risk', which started its career before 1970, built steadily to a peak around 2000. 'Market failure' - a phrase implying confidence that environmental externalities could be internalised, bringing about 'market success' - began its rise about 1970, peaking in the 1990s. Mentions of the 'Kuznets curve' - according to which continued development of 'the market' leads to a decline in environmental impact - took off in the late 1970s. 'Environmental economics' began its career around 1970, 'ecological economics' a bit before 1990 . 'Natural capital' began to go into linguistic circulation around 1985. During the first George Bush regime in the US, the phrase 'no net loss' reflected the growth of a set of institutions devoted to equating biota in different locations with each other as a prelude to trading (Robertson 2002). 'Ecosystem services,' a phrase that implies commensurability between clean water or air and the outputs of fast food restaurants or auto repair shops, made its first significant appearance just before 1980 and has risen in popularity ever since (Gómez-Baggethun et al. 2010); by 1997, it was possible for the environmental economist Robert Costanza to characterize the Earth itself as a 'very efficient, least-cost provider of human life-support services', with a value of between US\$16-54 trillion. In 2006, 'carbon neutral' - a phrase connoting the presence of institutions for valuing and trading increments of climate benefit became the New Oxford American Dictionary's 'word of the year' ${ }^{6}$

Contending simultaneously with imperatives to protect conditions of production and to cope with profitability crisis, in short, necessitated decades of hard, culturechanging work in thousands of offices, field sites, computers, labs, meeting rooms, classrooms, trading floors and airplanes. It was, in part, the matrix of new, commodification-ready environmental objects that resulted that made it so easy for a relatively small group of actors to insert what might otherwise seem the far-fetched construct of carbon trading into global policy.

\section{Parallel Developments}

By the late 1990s, a growing technocracy devoted specifically to carbon trading was busy creating yet further novel objects such as 'tons of CO2 equivalents' (Bumpus 2011). Carbon trading's two components - emissions trading (cap and trade) and offset trading - have been analyzed at length elsewhere (Gilbertson and Reyes 2009; Lohmann 2005, 2009, 2010b). However, they have seldom been compared in much detail with other, similar markets developed during the neoliberal era. Putting carbon trading in this wider context helps highlight some of its salient features while enabling fresh perspectives on the development of climate politics. 
One fascinating parallel is with the markets in 'tradable quotas' (TQs) legislated into existence in several Atlantic and Pacific ocean fisheries during the 1990s. The TQ system is a sort of 'cap and trade for fish', and cap and trade a sort of TQ system for greenhouse gases. Both systems trade in 'rights to exploit' - whether fish stocks or the earth's carbon-cycling capacity. Both systems, too, use dispossession to prepare a regime in which 'efficiency' purportedly coincides with environmental protection. In Norway, fish previously 'regarded as a common heritage of the coastal people' are 'expropriated, without compensation, and given, free of charge, as private property to a small elite' (Holm 2002). In various US Pacific fisheries, rights to fish for halibut and sablefish are divided among individual fishers, and rights to Alaska pollock among processors and fishing cooperatives. Under the Kyoto Protocol and EU ETS, meanwhile, the earth's carbon-cycling capacity is distributed, again usually free of charge, to Northern industrialized nation-states, according to the principle (known as 'grandfathering') that the most pollution rights should be awarded to those who have polluted most in the past.

In the carbon case, of course, the rights issued to Northern industry are not exclusionary (nor are they permanent, since the number of rights given out can be reduced over time). Nations and industries in the global South are allowed to continue using global carbon sinks without restriction. Nonetheless, the creation of tradable emissions rights is a form of privatization channelling disproportionate benefits to Northern industry and finance. For one thing, the rights granted to richer countries under Kyoto and the EU ETS come in the form of commodities, unlike the permissions allowed to the global South. These commodities have proved lucrative to many fractions of capital: electricity generators, steel firms, speculators and many others. ${ }^{7}$ In addition, the rights that European and some other industrialized country governments distribute to their major polluting industries - again for the most part free of charge - can be conceptualized in part as legal and economic guarantees protecting Northern industries' power to harm others through their overuse of global carbon-cycling capacity. ${ }^{8}$ In this respect, carbon trading bears a resemblance to the characteristic trade treaties of the neoliberal era, such as the North American Free Trade Agreement and Host Government Agreements, which enhance profits by effectively granting corporations immunity from local environmental laws (McCarthy 2007).

Tradable quota regimes in fisheries are supposed to encourage the exit of 'inefficient' fishers from an overcapitalized industry (Mansfield 2007), leaving a 'new class' of fish-owners who are 'intensely preoccupied with the health of the resource, since the return on their investments depends on it' (Holm 2002). So, too, carbon cap and trade regimes are intended to recruit the private sector to environmentalism via imposed restrictions on emissions and a mounting 'carbon price' incorporated into business decision-making. Both regimes, in addition, devolve private property rights to corporations, groups or individuals through an enormous prior expansion of state control. As Becky Mansfield emphasizes in her work on 'neoliberalism in the oceans', TQ systems became possible only after seacoast states had enclosed 30 per cent of the oceans and 95 per cent of the world's fisheries through the establishment of 200-mile zones ultimately enshrined in the Law of the Sea (Mansfield 2007: 65). Under the EU ETS, similarly, European states had to entitle themselves to global carbon sinks before calculating and 'producing' commodified rights for donation to high-emitting 
corporate sectors - although in this case the objective from the outset was much more clearly to set up a trading system. ${ }^{9}$

In transforming environmental challenges (overfishing, global warming) into questions of capital management, TQs and cap and trade also both put distinctive, and similar, structural stresses on the scientific framework that is supposed to ensure their effectiveness. TQ systems require fishery science to come up with some approximation to 'sustainable limits' to fish catches and to subscribe to a belief in 'equilibrium' - requirements that are at odds with both vernacular and chaos theoryinfluenced conceptions of the marine environment (Smith 1990). ${ }^{10}$

\section{Carbon Offsets and Wetlands Banking}

The second component of carbon trading - carbon offsets - also finds instructive parallels among other ecosystem markets that have sprung up in recent decades. One example is wetlands banking - a scheme developed in the US during the 1980s and 1990s as a way of making it easier for builders to comply with restrictions on dredging or dumping in swampy areas (Robertson 2004). Under wetlands banking, developers, instead of having to suspend operations, move to another site, or fashion 'compensatory wetlands' on the same parcel of land they are building on, can buy pre-packaged 'wetlands credits' from other locations to cover the damage they do. Just as carbon offsets produced through the Kyoto Protocol's Clean Development Mechanism (CDM) allow their ultimate buyers (mainly in Europe) to go on burning fossil fuels at the same rate at a time of incipient emissions caps, wetlands credits confer on builders the right (which regulation would otherwise curtail) to bulldoze unique sites. In addition to loosening regulatory constraints on business, carbon offset trading offers lucrative speculative opportunities, and not surprisingly is today dominated by the City of London and Wall Street (UN Risoe Centre 2012). ${ }^{11}$

Unlike carbon offset trading, wetlands trading was not legislated into existence by national states and international treaties. Rather, as Morgan M. Robertson recounts in a series of brilliant papers, it was the brainstorm of state and federal highway agencies and Illinois private building contractors looking for innovative ways of complying with 1970s US federal clean water legislation (Robertson 2007: 115-16). Yet carbon credits and wetland credits are similar in that they are both created through techniques that reduce qualitative ecological/social processes to a simplified, standardized set of quantifiable 'ecosystem services', thus redefining nature as a 'stable external presence'. 'Wetland loss at the site of impact must be rendered commensurable with wetland gain at the site of banking in a regular and reliable way' (Roberston 2007: 118).

The consequence is what Robertson calls an 'inconcludable dynamic of contradictory, and perhaps cyclic impulses’ (Robertson 2007: 122). On the one hand, scientists working for wetland banks use algorithms and professional judgment to assign numerical scores to the various 'functional benefits' of banking sites (habitat provision, plant diversity, peak flow attenuation, floodwater storage and so forth). On the other hand, the US Army Corps of Engineers, tasked with quantifying the impacts of construction, has little 
choice, due to lack of time and expertise, but to measure damage in acres. Bankers, suspicious that the mismatch is costing them profits, have proposed multiplying the number of commodities on offer, so that a builder who has reduced 'hydrologic function' at a certain site by three units and 'duck habitat' by four units can purchase separate credits, perhaps even at different banks, in mitigation. But the more ecological sensitivity is incorporated into the commodity, the less trade and liquidity is possible. It would be impossible, for instance, to create the ecosystem function 'floodwater storage for the Kishwaukee River basin’ outside the Kishwaukee River basin. Ecosystem science eventually comes up hard against the 'generalizing abstractions that characterize the internal logic of capital', setting off conflicts among bankers, regulators, and scientists alike. The institutions of wetlands banking, Robertson concludes, 'have not even agreed upon what the commodity is that they wish to measure' - in contrast with the institutions structuring markets in, say, wheat or microchips.

The parallels with carbon offset markets are unmistakable. Here, too, commodity construction requires heroic abstractions and (as also with TQ fishery systems) institutions that attempt to restructure nature as a stabilizable external entity. In order to be made quantifiable, divisible, standardizable and tradable, climate benefit and climate harm are conceptualized, in linear fashion, in terms of the flow of $\mathrm{CO} 2$ molecules -

a better climate $=$ reductions in $\mathrm{CO} 2$ emissions

- thus obscuring both uncertainty and the geoecological roots of the climate crisis in the unsustainable transfer of fossil carbon into an above-ground system comprising atmosphere, oceans, vegetation, soils and so forth. Supplementary acts of commensuration quickly follow:

$\mathrm{CO} 2$ reduction in place $\mathrm{A}=\mathrm{CO} 2$ reduction in place $\mathrm{B}$

$\mathrm{CO} 2$ reduction through technology $\mathrm{A}=\mathrm{CO} 2$ reduction through technology $\mathrm{B}$

$\mathrm{CO} 2$ reduction through conservation of biota $=\mathrm{CO} 2$ reduction through keeping fossil fuels in the ground ${ }^{12}$

A new construction, 'carbon dioxide equivalent', or CO2e, is derived from further gross oversimplifications:

$$
\begin{gathered}
\mathrm{CH} 4=21 \text { X CO2 } \\
\mathrm{N} 2 \mathrm{O}=310 \times \text { CO2 } \\
\mathrm{HFC}-23=11,700 \mathrm{X} \mathrm{CO}^{13}
\end{gathered}
$$


Carbon dioxide reductions mandated by cap and trade schemes are then made equivalent to offsetting activities outside the jurisdiction of the scheme:

CO2e reduction under a cap = 'avoided' CO2e outside the cap

Activities at a wide variety of 'mitigation sites' can accordingly be used to generate credits enabling the continued use of fossil fuels at 'impact sites' such as power stations and iron and steel factories. For example, two dozen giant hog farms operated by Granjas Carroll de Mexico, a subsidiary of the US-based Smithfield Farms, today capture and burn the methane given off by the huge volumes of pig excrement they produce (hence 'avoiding' biotic $\mathrm{CH} 4$ emissions by replacing them with $\mathrm{CO} 2$ emissions, thus reducing $\mathrm{CO} 2 \mathrm{e}$ and quantifiably 'benefiting' the climate), then sell the resulting carbon credits to Cargill International and EcoSecurities.

Ultimately, as in wetlands trading, attempts to 'push ecological knowledge towards spawning further rounds of accumulation' via construction of such shaky equations 'may disrupt the very mechanics of accumulation' (Robertson 2007: 123). ${ }^{14}$ In carbon trading, the equivalence 'CO2e reduction under a cap = "avoided” CO2e outside the cap', which underpins all offset commodities, generates particular mayhem. For example, the EU, noting that refrigerant gas producers have upped their production of HFC-23 merely to be able to sell carbon credits for 'avoiding' it later, recently decided to ban such credits from the EU ETS as of 2013, citing their 'total lack of environmental integrity' (Connie Hedegaard quoted in Reyes 2011). But the contradictions generated by attempts to apply the equation are far more general. To manufacture offsets by counting 'avoided CO2 emissions', a baseline must first be established with which to compare current molecular activity. The baseline must be unique, since exchange requires a single value. Hence the calculation of 'avoided emissions' not only demands the sort of knowledge human beings have never before attained, attempted, or believed possible. (Which of all the scenarios that counterfactual historians and novelists have imagined might have followed a Nazi invasion of Britain is the 'true' one?) It also demands, impossibly, that this knowledge come in the form of an extremely precise quantification of the associated molecular movements and that this quantification be open to a process of checking and verification which, that will never become available to anyone. ${ }^{15}$ Corporations are able to print climate money without much fear of sanction, since no stable distinction between counterfeit and legitimate currency can be maintained (The Munden Group 2011: 17). Already, different methodologies for singling out a baseline have resulted in calculations of forest carbon credits that range over two orders of magnitude (Griscom et al. 2009). Ultimately, this may be a step too far even for a financial system accustomed to lax reserve capital controls and complex financial derivatives such as credit default swaps (The Munden Group 2011). ${ }^{16}$ As Robertson puts it, if some ecological knowledges 'work' for capital, others do not.

\section{A Longer-Term Historical Logic}

A final social-science tool can help place carbon trading in an even broader context, that of historical cycles of accumulation, by drawing on the work of 
historians, sociologists and geographers such as Giovanni Arrighi, David Harvey and Jason W. Moore. Such theorists take a long view, arguing that profit crises, financialization, and attempts to 'internalize' threats to business expansion created by previous expansions have unfolded time and again over many centuries in varied ways.

Arrighi, for example, posits a succession of global 'systemic cycles of accumulation', each with a different geographical centre and each characterized by a different attempt to bring certain (emergent or longstanding) 'costs' within the 'economizing logic of capitalist enterprise'. In one such cycle centered on The Netherlands during the 17th and 18th centuries, Arrighi argues, a Dutch business class organized in the state found it to its advantage to internalize increasingly expensive 'protection costs' - costs of exercising force and making war - that an earlier, Genoese cycle between about 1450 and 1625 had found easier to 'externalize' to the Iberian imperial-territorial states. By 'economizing' on brutality and making it pay to a greater extent than other, more territoryobsessed powers could, Dutch chartered companies were able to become 'selfsufficient and competitive in the use and control of violence' in the East Indies (Arrighi 1994), 'producing' their own protection at costs that were lower and more predictable than the tribute or extortions extracted from caravans and ships by local powers (Steensgard 1981). Similar innovations allowed the Dutch to squeeze out Spanish influence in the Baltic and gain power over the Atlantic slave trade (Arrighi 1994: 155).

The British-centered cycle that followed from about 1775 to 1925, while continuing to internalize protection costs (ensuring agro-industrial imports), superseded the increasingly crisis-ridden Dutch cycle partly by bringing production, especially industrial production, 'within the organizational domain of capitalist enterprises', subjecting them to the investment planning and 'economizing tendencies typical of those enterprises' (Ibid.: 177). This cycle - to whose productivity and flexibility coal, railroads and an increasingly commercialized agriculture were crucial - in turn succumbed to a US-dominated cycle in which oil-based processes of suburbanization, globalization and Green Revolution agriculture became crucial. This cycle internalized not only protection and production costs, but also transaction costs, vertically integrating business organizations within a single organizational domain in a way that made the costs associated with the transfer of intermediate inputs through the long chain between production and consumption more predictable and calculable (Ibid.: 218, 240, 241, 287). Railways, marketing, mail order, mass retail, computers all helped structure a high volume of market transactions within single enterprises. Capital sunk in specialized machinery mandated corporate control over prices and thus suspension or supersession of ordinary market mechanisms (Galbraith 1967). Post-1980 developments such as just-in-time production and containerized shipping further rationalized the process (Mirowski 2011, Levinson 2008). Eventually, however, as in previous cycles, a profitability crisis followed by a bout of speculative excess and financialization began to generate 'the chaotic ferment' (to use the words of another theorist of long capitalist cycles, David Harvey) out of which yet another mode of organization, with its own physical infrastructure, is now growing (Arrighi 2007: 223). Arrighi thus anticipates the rise, in the 21st century, of a new, Chinacentred cycle. 
An interpretive framework that emphasizes the importance of accumulation cycles explains a great deal about carbon markets that baffles and frustrates their mainstream proponents. According to mainstream accounts, for example, carbon trading will work if states follow the findings of scientific bodies in setting and enforcing stringent, progressive emissions caps (Sandbag 2011a; California Environmental Protection Agency 2011). Trading in emissions and offsets will then ensure that this scientifically 'correct' outcome is achieved at the lowest cost. Presupposing the existence of a technocratically rational, strong state independent of business, and conceiving of markets primarily as 'efficiency machines', this account tends to downplay the role of profits, productivity, accumulation crisis, commodification and regulatory capture in market construction and market performance. Phenomena such as the inability of states to set strict emissions caps, identify the commodity being traded, or control carbon scams appear as irksome pathologies or side issues. When such phenomena persist despite their supposed 'abnormality', well-intentioned mainstream observers find themselves at sea, impotent to suggest any solutions other than more 'political will' or better technique.

Theories of accumulation cycles provide useful interpretive tools for avoiding this quagmire. Instead of treating the environmental ineffectiveness of carbon markets as a worrying but temporary anomaly, the theory treats it as a predictable - and partly successful - response to the stresses on capital building up at the tail end of a fossilfuelled US-centred accumulation cycle. Such theories, grasping the enduring importance of state action in safeguarding conditions for accumulation, as well as the key role that fossil fuels continue to play in labor productivity throughout industrialized societies, find the unambitious emissions targets and production of implausible emissions-cut 'substitutes' that have characterized carbon markets entirely unsurprising. Well aware of the nature of the 'turn to finance' that typically occurs at the close of accumulation cycles, such theories also make explicable why carbon trading - along with other 'green capitalist' initiatives - originated partly from, and continues to be dominated by, a financial sector whose bias is toward creating novel sources of profit rather than halting the flow of fossil fuels out of the ground. ${ }^{17}$ From this perspective, it is only to be expected that emissions caps will be set just strictly enough to create scarcity for a new market, but not strictly enough to threaten the role of coal and oil in capital accumulation, and that further plans to financialize forests and land as carbon sinks are proceeding apace under the supportive eyes of many on Wall Street (Carbon Trade Watch 2010). The theory of accumulation cycles thus usefully redirects the attention of strategy-minded activists to the underlying drivers of global warming while explaining why carbon trading, and the 'market environmentalist' ideology that supports it, will remain less than credible responses to climate crisis. By linking false climate solutions to other manifestations of the neoliberal response to profit crisis, it also suggests the importance of alliance-building between carbon market critics and wider social movements countering privatization, appropriation and commodification.

\section{Conclusion}

In 2010, data from $\mathrm{BP}$ has shown, $\mathrm{CO}_{2}$ emissions from burning fossil fuels rose at their fastest rate in four decades. So devastating are the implications of this trend that many Northern debates about how to reverse it seem to have little time to pause to consider lessons from history and sociology. This article has tried to suggest the 
strategic hazards of this shortsightedness, as well as the advantages of openness to more varied interpretive approaches to climate change politics.

Building more effective climate movements is largely a matter of interpretation and reinterpretation, which are in turn a matter of contextualization and

recontextualization. Climate activists can benefit from 'going wide' into the study of market environmentalisms that have evolved together with carbon trading; from 'going deep' into the insights of actor-network theory about the genesis and limitations of commodity-ready environmental objects; and from 'going long' into the historical investigation of accumulation cycles. Rather than being forced to beat their heads against the wall erected by the economistic premise that, given enough time and tweaks, carbon trading 'must' someday be made to work, climate activists can thereby gain a more detailed, nuanced and encouraging picture of the field of possible action on climate change. 
On the construction of 'the economy' see Mitchell (2002). Actor network theorists such as Mitchell and Michel Callon describe a process of 'framing' or 'disentanglement' through which objects such as 'the economy' and 'the environment' are not only described, defined and measured, but also constituted, nurtured, 'performed' and transformed by a multitude of practices of calculation and governmentality originating in academia, government bureaucracies and other institutional settings, as well as 'in the wild' among economic agents at large (Callon 2005). 'Expert knowledge', in the words of Mitchell, 'works to format social relations, never simply to report or picture them' (Mitchell 2002: 118). For example, double-entry bookkeeping 'was devised to account for business transactions, but once established, it altered these transactions by changing the way businessmen interpreted and understood them' (Carruthers and Espeland 1991, see also MacKenzie 2009). For an application to carbon markets specifically, see, e.g. Lohmann (2005).

2 Al Gore, for example, has attributed environmental crisis mainly to the incorrect 'calculations by which our economy is governed' (Independent, 7 July 2007).

The notions of hybrid and monster are important in actor-network theory due in part to the emphasis it places on the mixed social-natural-technical nature of agency (Law 1991).

4 Contingent valuation, in which subjects are schooled in how to assign monetary value to unmarketed items like clean air, is one example of how an economic valuation technique 'performs' or creates a new set of agents. See Lohmann (2009).

Of course, like all radical innovations, such post-1970 environment-economy confections were made from ingredients assembled in earlier eras, some of which had been known under other names. The phrase 'natural resource management,' for example, which made a slow start into common usage in English around 1965 prior to a very steep increase starting in the early 1980s, combined a nature/society divide that had been built up since at least the 18th century with the equally hoary notion that the resulting 'nature' could be construed as raw material and subjected to rational planning. Similarly, the idea that pollution could in theory be 'optimised' through market bargaining, which eventually developed into the carbon trading of the Kyoto Protocol and the EU Emissions Trading Scheme, originated in the late 1950s with the US economist Ronald Coase, who had been working with an idea of 'externalities' formalized by Arthur Pigou in the earlier 20th century and invented by the philosopher Henry Sidgwick in the 19th. The term 'ecosystem', similarly, had been invented in the 1930s (by Arthur Tansley) before being developed by Howard Odum in the 1950s through calculable models based on electrical circuits, which found an echo not only in the perspex pipes of A. W. Phillips's 1949 MONIAC hydraulic economics computer modelling a 'national economy' but also in the Global Circulation Models and other 'worlds within machines' that began to emerge in the late 1950 s in climatology. markets - the carbon credits (Certified Emission Reductions or CERS) are cheaper because investments in the developing world are considered riskier' (Liverman 2009). 
8 Liverman (2009) glosses this 'grandfathering' regime as follows: 'Because the baseline for the reductions was based on emissions in 1990 the atmosphere was effectively "enclosed” according to pollution levels in 1990. The larger environmental narrative here is that of "prior appropriation" whereby those who first polluted the atmosphere then acquire a right to pollute under international law.'

9 The subsequent legal wrangles also appear to be harder to sort out than in the case of fisheries. All of the following questions, for example, have been the subject of extended dispute in the arenas of law and diplomacy: Who owns the rights to the carbon in New Zealand forests (Lohmann 2006: 127)? Who owns the millions of tonnes of stolen EU pollution rights that went into widespread circulation in early 2011 before anyone had rumbled the computer hackers that had lifted them (Lohmann 2010a: 117-120; Carbon Finance Online 2012)? Whose legal responsibility are the carbon dioxide molecules coming out of smokestacks in Shenzen if they are being emitted in the course of producing consumer goods for the US or Europe (Peters et al. 2011)? Is the EU exceeding the legal authority by bringing aviation under the EU ETS and thus regulating molecules emanating from machines that are used to start jet engines in Los Angeles or Beijing (Clark 2011)?

As Holm (2001) notes dryly, sociologists of fisheries tend to have better biological theories of fish than do the fish biologists who work across disciplinary boundaries with the economist-managers of TQ systems, who in turn are better sociologists than the academic fishery sociologists in that they have been able to entrench the socialtechnical infrastructure required for TQs.

The financial sector, however, is growing increasingly skeptical of the carbon market, with many banks and funds closing carbon trading desks, withdrawing from exchanges, divesting themselves of carbon businesses and shedding staff.

12 In current CDM forestry offsets, temporary CERs (or tCERs) must in the end be replaced with energy-based offsets. However, this does not eliminate dependence on this equation. The hundreds of millions of tonnes of offsets that would be produced by offsets under proposals for Reducing Emissions from Deforestation and Forest Degradation (REDD) also rely completely on this equation.

13 All these equations oversimplify in the sense that each gas behaves qualitatively differently in the atmosphere and over different time spans, and the control of each has a different effect on fossil fuel use. Even the IPCC finds itself revising its calculations of the CO2-calibrated 'Global Warming Potential' (GWP) of various gases every few years, and insists on giving gases different GWPs over 20-year, 100-year and 500-year time horizons. But even such token caveats cannot be accommodated by a market that requires a single, stable number in order to make exchange possible. The UN carbon market, for example, disregards its own IPCC's recent revisions in GWP figures, discards 20-year and 500-year figures, and ignores the (misnamed) 'error bands' specified by the IPCC (in the case of HFC23, plus or minus 5000 CO2-equivalents). For further discussion, see, e.g., MacKenzie, op. cit. Oin one example of the fragility of such equations, in 2007 the 'global warming potential' or GWP of HFC-23 was revised upwards from 11,700 to 14,800 by the Intergovernmental Panel on Climate Change - although the UN carbon market continues to use the earlier equation. 
Technocratic institutions that reflect on this problem tend in the end to throw up their hands and bequeath the whole question to what they hope will be the greater 'technical' expertise of posterity. See, e.g., United Nations Development Programme (2012). As Michael Gillenwater (2012) of the Greenhouse Gas Management Institute confesses, 'we don't appear to have a handle on a concept we have championed as integral to the policies we have created.'

As The Munden Project (2011) notes, the difficulty of verifying commodity quality eclipses those experienced even in financial derivatives markets. Oil futures markets, for instance, work with an underlying asset that, although infinitely variable, can be located, divided up, and its quality verified at any point along the user chain according to workable, standard criteria. The carbon offset commodity cannot be specified in the same way.

17 Members of the International Emissions Trading Association, for example, promote, in addition to increased use of the emissions 'equivalences' outlined above, sweeping standardization of climate commodities, rubber-stamp regulation, banking and borrowing of carbon pollution credits across compliance periods, increased participation of financial intermediaries, no buyer liability for fake products and an unregulated over-the-counter market that would encourage speculation. Some also make money by inducing carbon price volatility (Lohmann 2011).

\section{BIBLIOGRAPHY}

151.

Arrighi, G. (1994) The Long Twentieth Century: Money, Power and the Origins of our Time, London: Verso,

Arrighi, G. (2007) Adam Smith in Beijing: Lineages of the 21st Century, London: Verso.

Bavington, D. (2010) 'From Hunting Fish to Managing Populations: Fisheries Science and the Destruction of Newfoundland Cod Fisheries', Science as Culture 19 (4): 509-28.

Buck, D. (2007) 'The Ecological Question: Can Capitalism Prevail?' Socialist Register 2007: 60-71.

Bumpus, A. G. (2011) 'The Matter of Carbon: Understanding the Materiality of tCO2e in Carbon Offsets,' Antipode 43(3): 612-638.

California Environmental Protection Agency, Air Resources Board (2011), Supplement to the AB 32 Scoping

Plan Functional Equivalent Document, Sacramento: California Environmental Protection Agency.

Callon, M. (2005) 'Why virtualism paves the way to political impotence. Callon replies to Miller', Economic Sociology European Electronic Newsletter, 6, 2, 3-20: 9

Carbon Finance Online (2012) 'Court rules EUA “phishing” victim entitled to compensation', Carbon Finance

Online, 18 January 2012.

Carbon Trade Watch (2010), No REDD: A Reader, Barcelona: Carbon Trade Watch.

Carruthers, B. G. and Espeland, W. (1991) 'Accounting for rationality: Double-entry bookkeeping and

emergence of economic rationality', American Journal of Sociology 97: 36.

Clark, P. (2011) 'United Warns EU on Emissions Scheme’, Financial Times, 3 April 2011.

Galbraith, J. K. (1967) The New Industrial State, London: Penguin.

Gilbertson, T. and Reyes, O. (2009) Carbon Trading: How it Works and Why it Fails, Uppsala: Dag

Hammarskjold Foundation.

Gillenwater, M. (2012) 'How do you explain additionality?’ Online. Available from HTTP:

<ghginstitute.org/2012/01/25/how-do-you-explain-additionality/> (Retrieved 1.2.2012).

Gómez-Baggethun, E.R. de Groot, P.L. Lomas, C.M. (2010) 'The History of Ecosystem Services in Economic

Theory and Practice: From Early Notions to Markets and Payment Schemes’ Ecological Economics 69: 1209-1218.

Griscom, B., et al. (2009), 'Sensitivity of Amount and Distribution of Tropical Forest Carbon Credits

Depending on Baseline Rules’, Environmental Science and Policy 12: 897-911.

Holm, P. (1999) 'Fisheries Resource Management as a Heterogeneous Network' Society.

Holm, P. (2001) The Invisible Revolution: The Construction of Institutional Change in the Fisheries, unpublished Ph. D. thesis, Tromso: Norwegian College of Fishery.

Holm, P. (2002) 'Which Way is up on Callon? A Review of a Review: Daniel Miller's 'Turning Callon the Right Way Up.' On Michel Callon: The Laws of the Markets’, Online. Available from HTTP: 
<www0.nfh.uit.no/dok/which_way_is_up0.pdf: 17> (Retrieved: 22.3.2012). Routledge.

Law, J., (ed.) (1991) A Sociology of Monsters: Essays on Power, Technology, and Domination, New York:

Levinson, M. (2008) The Box: How the Shipping Container Made the World Smaller and the World Economy

Bigger, Princeton: Princeton University Press.

Liverman, D. M. (2009) 'Conventions of climate change: constructions of danger and the dispossession of the atmosphere', Journal of Historical Geography 35(2): 279-296.

Lohmann, L. (2005) 'Marketing and Making Carbon Dumps: Commodification, Calculation and

Counterfactuals in Climate Change Mitigation', Science as Culture 14(3): 203-235.

Lohmann, L., (ed.) (2006), Carbon Trading: A Critical Conversation on Climate Change, Privatization and

Power, Uppsala: Dag Hammarskjold Foundation.

Lohmann, L. (2009) 'Toward a Different Debate in Environmental Accounting: The Cases of Carbon and Cost-

Benefit', Accounting, Organisations and Society 34(3-4): 499-534.

Lohmann, L. (2010a), 'Los “Mercados Extraños” y la crisis climática ' in Bravo, E. (ed.) Crisis financiera o

crisis civilizatoria, Quito: Manthra Editores.

Lohmann, L. (2010b) 'Uncertainty Markets and Carbon Markets: Variations on Polanyian Themes', New

Political Economy 15: 225-254.

Lohmann, L. (2011) 'Financialization, Commodification and Carbon: The Contradictions of Neoliberal

Climate Policy’, Socialist Register 2012.

MacKenzie, D. (2009) 'Making things the same: Gases, emissions rights and the politics of carbon markets',

Accounting, Organizations and Society, 34 (3-4): 440-455

Mansfield, B. (2007) 'Neoliberalism in the Oceans: "Rationalization”, Property Rights, and the Commons

Question', in N. Heynen et al. (eds) Neoliberal environments: false promises and unnatural consequences, London: Routledge.

McCarthy, J. (2007) 'Privatizing Conditions of Production: Trade Agreements as Neoliberal Environmental

Governance', in Heynen, N. et al. (eds) Neoliberal Environments: False Promises and Unnatural Consequences,

London: Routledge.

Mol, A. P. J. (1995) The Refinement of Production, Utrecht: International Books.

P. Mirowski and D. Plehwe (eds) (2010) The Road from Mont Pelerin: The Making of the Neoliberal Thought

Collective, Cambridge: Harvard University Press.

Mirowski, P. (2011) Science-Mart: Privatizing American Science, Cambridge: Harvard University Press.

Mitchell, T. (2002) Rule of Experts: Egypt, Technopolitics, Modernity, Berkeley: University of California

Press.

Pahle, M., Fan, L. and Schill, W.-P. (2011), 'How Emission Certificate Allocations Distort Fossil Investments:

The German Example', Energy Policy 39(4): 1975-87.

Pálsson, G. (1998) 'The Virtual Aquarium: Commodity Fiction and Cod Fishing', Ecological Economics 24 (2-

3): 275-288.

Peck, J. (2010) Constructions of Neoliberal Reason, Oxford: Oxford University Press;

Peck, J. and Tickell (2002), A., 'Neoliberalizing Space', Antipode 34 (3): 380-404.

Peters, G.P. et al. (2011) 'Growth in Emission Transfers via International Trade from 1990 to 2008',

Proceedings of the National Academy of Sciences, 108 (21).

Point Carbon (2012a) 'Barclays shutters U.S. emissions trading desk', 19 January; 'Rock-bottom AAU prices

could spur CER sell-off: sources', Point Carbon 12 January 2012.

Point Carbon (2012b) 'Carbon stocks suffer as investors quit the market', Point Carbon, 16 January 2012.

Point Carbon (2012c) 'CERs fall 5 pct, hit record low on oversupply, weak demand', Point Carbon, 16 January

2012.

Reuters (2011) 'Polluters Winners from Carbon Scheme’, Reuters 23 June 2011.

Reyes, O. (2011) The EU Emissions Trading System: Failing at the Third Attempt, Barcelona: Corporate

Europe Observatory and Carbon Trade Watch.

Robertson, M.M. (2000) 'No Net Loss: Wetland Restoration and the Incomplete Capitalization of Nature', Antipode 32(4): 463-93.

Robertson, M. M. (2004) 'The Neoliberalization of Ecosystem Services: Wetland Mitigation Banking and

Problems in Environmental Governance’, Geoforum 35(3).

Robertson, M. M. (2007) 'The Neoliberalization of Ecosystem Services: Wetland Mitigation Banking and the

Problem of Measurement' in N. Heynen et al. (eds) Neoliberal environments: false promises and unnatural

consequences, London: Routledge.

Sandbag (2010) The Carbon Rich List, London: Sandbag.

Sandbag (2011a), Buckle Up! Tighten the Cap and Avoid the Carbon Crash, London: Sandbag

Sandbag (2011b) Carbon Fat Cats 2011, London: Sandbag.

Smith, M. E. (1990) 'Chaos in Fisheries Management', Maritime Anthropological Studies 3 (2).

Steensgard, N. (1981) 'Violence and the Rise of Capitalism: Frederic C. Lane's Theory of Protection and

Tribute', Review 5(2): 259-60. 
The Munden Group (2011), REDD and Forest Carbon: Market-Based Critique and Recommendations, New York: The Munden Group

UNDP (2011) 'Forest Carbon Accounting: Overviews and Principles’, Online. Available from HTTP: <www.undp.org/climatechange/carbon-finance/CDM/resources.shtml> (Retrieved: 15.3.2011).

UN Risoe Centre (2012) 'CDM Pipeline' Online. Available HTTP: <cdmpipeline.org/cdm-projects-type.htm> (Retrieved: 1.2.2012). 